\title{
Interaction of OGG1 with NKX3.1 due to oxidative DNA damage
}

\author{
Elif ISEL 1 (D), Bilge DEBELEC BUTUNER 2* (D)
}

1 Department of Biotechnology, Graduate Faculty of Natural and Applied Science, Ege University, İzmir, Turkey.

2 Department of Pharmaceutical Biotechnology, Faculty of Pharmacy, Ege University, İzmir, Turkey.

* Corresponding Author. E-mail: bilge.debelec@ege.edu.tr (B.D.B.).

Received: 30 June 2020 / Revised: 16 February 2021/ Accepted: 23 February 2021

\begin{abstract}
Oxoguanine DNA glycosylase 1 (OGG1) is a member of base excision repair, responsible for the repair of 8-oxoG base damage induced by reactive oxygen species. As oxidative DNA damage contributes to prostate carcinogenesis, investigating the interaction of OGG1 with prostate-specific proteins, which function in DNA damage and repair mechanisms in prostate cells, is important to determine appropriate therapeutic targets and ultimately support the cancer treatment strategies. Therefore, in this study we investigated the protein-protein interaction of OGG1 with androgen receptor (AR), which is critical for prostate cell proliferation as well as NKX3.1, which is a tumor suppressor protein specific to prostate cells. In addition, S326C, a polymorphic variant of OGG1 formed by a single amino acid change, has been reported in literature to cause a deficiency in repair activity leading OGG1 to be a predisposition factor for prostate cancer. In our immunoprecipitation results, OGG1 was detected to physically interact with NKX3.1 and AR upon increased oxidative DNA damage by menadione treatment. Further, immunofluorescence microscopy results showed that OGG1 localizes in the nuclear speckles at basal and induced level of DNA damage. Although NKX3.1 co-localize with OGG1 in the nucleus, localization of OGG1 was not observed in nuclear speckles in the presence of NKX3.1 possibly due to reduced oxidative DNA damage in NKX3.1 expressing cells. However, reduced physical association of OGG1-S326C variant form in comparison to wild type and further no co-localization of variant form with NKX3.1 was detected supporting the idea that OGG1-S326C variant form contributes to the prostate carcinogenesis.
\end{abstract}

KEYWORDS: Prostate cancer; oxidative DNA damage; oxidative DNA damage repair; OGG1-S326C polymorphic variant; protein-protein interaction.

\section{INTRODUCTION}

Genome is constantly exposed to endogenous and exogenous mutagens, such as reactive oxygen species (ROS) in living organisms. They are highly reactive cellular byproducts that attack to DNA and induce DNA damage, which is associated to mutagenesis and carcinogenesis [1-4]. 7,8-dihydro-8oxoguanine (8-oxoG), the oxidized product of guanine base, is the most frequent oxidative DNA lesion in the genome. It is estimated that up to 100.000 8-oxoG lesions can occur in the DNA of each cell per day. 8-oxoG is highly mutagenic because it can match adenine instead of cytosine during DNA replication causing G:C to T:A transversion [5]. In eukaryotic cells, 8-oxoG is mainly repaired by the base excision repair (BER) mechanism. The human OGG1 gene encodes 8-oxoG DNA glycosylase (OGG1), which is a DNA glycosylase/AP-lyase and a functional BER element [6] responsible for removing 8-oxoG from 8-oxoG:C base pairs in double-stranded DNA $[7,8]$.

It is known that oxidative DNA damage contributes to prostate carcinogenesis [9, 10]. In malignant prostate tissue, there is a significant increase in mutagenic DNA base lesions rate such as 8-hydroxyadenine (8-oxoA) and 8-hydroxyguanine (8-OHdG) caused by oxidative damage. In addition, this increase occurs in benign prostate tissue with advancing age [10-12].

DNA damage repair mechanism is strongly linked to tissue-specific cellular factors that regulate cell proliferation and/or cell death. Therefore, interaction of OGG1 in prostate specific factors such as androgen receptor (AR) might regulate its function in tissue specific conditions. Prostate cells require androgens for maintenance and proliferation and further, AR is a critical cellular player in the proliferation of prostate cells and in the treatment of primary prostate cancer. In addition, contribution of AR to antioxidant response and 
regulation of antioxidant genes such as NADPH oxidases has already been described [13]. Although AR function is necessary to regulate the antioxidant response in prostate cells against basal oxidative stress, androgen signaling in oxidative damage-related DNA repair during the development of prostate cancer still needs to be investigated. Besides AR, an androgen-regulated gene, NKX3.1 also plays an important role in oxidative stress regulation via controlling the expression of ROS scavengers as a member of androgen signaling [14, 15]. It is also a prostate-specific tumor suppressor and loss of its expression has been reported in prostate tumors [16-18]. In addition, NKX3.1 is known to exert a tumor suppressive effect by activating the cellular response to DNA damage and enhancing DNA repair in oxidant cellular conditions. NKX3.1 also activates the expression of genes associated with DNA repair [19]. It contributes to the repair mechanism by migrating to the region where DNA damage occurs, thus it ensures the DNA repair proteins to recruit in the damaged area and increases their activation. Therefore, NKX3.1 increases cell survival via enhancing the repair of DNA damage [20,21]. It has been shown in a previous study that OGG1 has protein-protein interaction with AR and NKX3.1 upon treatment of cells with dihydrotestosterone and DNA double strand break inducer, etoposide [22]. Therefore, in the present study, we investigated the physical interaction of OGG1 with NKX3.1 and AR in repairing 8-oxoG base lesions under oxidative stress conditions.

Since the OGG1 enzyme is expressed abundantly in the prostate tissue, the most studied polymorphic variant S326C has been a subject of strong debate whether it is functional and alters cancer susceptibility by changing the damage repair activity [23]. The polymorphic variant of OGG1-S326C has been reported to found at frequencies of $23-43 \%$ in Caucasian and $40-60 \%$ in Asian populations [24, 25] and is associated with altered cancer risk in some populations. The presence of OGG1 genetic polymorphisms in prostate cancer patients supports the idea that defective DNA repair may be associated to the risk of prostate cancer [26]. Contradictorily, this variant OGG1 enzyme has been shown to be functional and does not make a significant difference in DNA repair activity and concluded that S326C had no effect on cancer risk comparison to wild type form [23]. Conflicting results in the literature has raised the question of whether subcellular localization of OGG1 S326C variant as well as its interaction with AR and NKX3.1 change upon induction of oxidative DNA damage. So, in this study protein-protein interactions of the OGG1 wild type (wt) and S326C polymorphic variant with NKX3.1 and AR as well as their co-localization with them was researched in prostate cancer cell lines LNCaP and PC-3.

\section{RESULTS}

\subsection{Interaction of OGG1 with NKX3.1 but not AR has been detected in LNCaP prostate cancer cell line}

In order to determine whether the OGG1 enzyme interacts with NKX3.1 and AR while performing the DNA repair activating function, immunoprecipitation (IP) performed by using antibodies of each interacting factor separately. LNCaP cells were treated with $10 \mathrm{nM}$ of R1881 for 24 hours to activate the AR signaling pathway in LNCaP cells, and with $0.1 \mathrm{mM}$ menadione for 3 hours to induce oxidative DNA damage. Immunoprecipitation results indicated that OGG1 is in direct physical interaction with NKX3.1 and AR depending on R1881 and menadione treatments (Figure 1A). Co-IP experiment was also designed to validate the IP OGG1 result. However, NKX3.1-OGG1 and AR-OGG1 interactions could not be observed although the successful precipitation of the corresponding protein of each antibody was shown (Figure 1B, C).

\subsection{OGG1-S326C polymorphic variant reduces OGG1-NKX3.1 protein interaction}

Since the polymorphic variant of a protein might affect its protein-protein interactions, we investigated the effect of S326C variation on interactions of OGG1 with AR as well as NKX3.1. The binding rates of both wild type (wt) and S326C polymorphic variant (S326C) proteins to AR and NKX3.1 separately were determined by using GST pull-down precipitation method. Recombinant GST-OGG1-wt and GSTOGG1-S326C proteins were expressed in E. coli and isolated from lysate by using GST beads. Since GST and OGG1 are 25 and $39 \mathrm{kDa}$ respectively, GST-OGG1 fusion protein expected to be observed at $64 \mathrm{kDa}$ on polyacrylamide gel. Recombinant GST-OGG1-wt and GST-OGG1-S326C proteins were determined to induce by IPTG induction for 3 hours and detected the solubilized proteins in the lysate and precipitated proteins in debris (Figure 2A). Thereafter, glutathione agarose beads were employed to separate the GST-fusion proteins from the lysate and the separated fusion proteins were detected on the polyacrylamide gel as shown by arrows (Figure 2B).

In order to confirm the protein-protein interaction results via GST pull-down method, PC-3 cells were transfected with either pSG5-AR or HM-NKX3.1 expression construct for ectopic AR and NKX3.1 expression 
respectively (Figure 3A) and the protein lysates were mixed with GST-OGG1-wt or GST-OGG1-S326C separately to determine the possible physical interactions as explained in the methods section. Each sample obtained from multiple steps of pull-down procedure were checked on the polyacrylamide gel and determined that GST-OGG1-wt and GST-OGG1-S326C fusion proteins were separated from the E. coli lysate properly by glutathione agarose beads (Figure 3B, bead-1 and supernatant-1). Further, upon treatment of the beads carrying GST-fusion proteins (bead-1) with PC-3 protein lysates, the beads carrying the interacted proteins (Figure 3B, bead-2 and supernatant-2) were obtained. Immunoblotting with OGG1 antibody showed the presence of OGG1-wt and -S326C in the supernatant and on the beads. AR labeling in ectopically AR-expressing samples of supernatant-2 group ensured the presence of AR in the lysate. However, although OGG1 was detected by immunoblotting in AR-expressing lysate sample of beads-2 group, no AR was seen on the same beads (labeled with black stars*) concluding that OGG1 and AR do not interact physically. When GST-pull-down procedure was performed with ectopically NKX3.1 expressing PC-3 protein lysates, NKX3.1 was detected higher than mock control sample indicating the protein-protein interaction of OGG1wt and NKX3.1 and in addition OGG1-S326C variant was determined to have less interaction with NKX3.1 (labeled with red stars*) suggesting that S326C mutation results in decreased protein-protein interaction between OGG1 and NKX3.1 (Figure 3C).

\subsection{OGG1 protein level decreases in the presence of NKX3.1 in prostate cancer cell lines}

As physical interaction of OGG1 and NKX3.1 might lead to a cellular co-localization of these factors upon activation of oxidative DNA damage repair machinery, we investigated if cellular localization of OGG1 changes in the presence of NKX3.1 and therefore PC-3 cells were transfected with HM-control/HMNKX3.1 vectors and treated with $0.1 \mathrm{mM}$ menadione for 3 hours to induce oxidative DNA damage. Samples were labeled with NKX3.1 and OGG1 antibodies and further analyzed under fluorescence microscope. OGG1 expression was observed to form nuclear speckles possibly at the oxidative DNA damage sites in the nucleus (Figure 4).

Further, regarding the expression pattern of OGG1, loss of speckle formation as well as reduced protein level also detected in ectopically NKX3.1 expressing PC-3 cells. Induction of oxidative DNA damage by menadione treatment was observed to enhance OGG1 protein level only in un-transfected cells that do not express NKX3.1 (Figure 5).

Thereafter, to check the co-localization in native expression conditions, LNCaP cells were treated with $10 \mathrm{nM}$ of synthetic androgen R1881 for 24 hours to enhance NKX3.1 expression and with $0.1 \mathrm{mM}$ menadione for 3 hours to induce DNA damage. Co-localization of NKX3.1 and OGG1 in the nucleus was detected in most of the cells. In addition, speckled expression pattern of OGG1 in the nucleus was confirmed in this cell line. Further, menadione treated cells determined to maintain OGG1 expression localized in the nucleus although NKX3.1 protein level suppressed due to menadione-induced oxidative DNA damage suggesting that OGG1 localizes in the nucleus regardless the presence of NKX3.1 (Figure 6).

Alteration in OGG1 expression was investigated upon NKX3.1 ectopic expression by western blotting in PC-3 cells that transfected with HM-control/HM-NKX3.1 vectors and treated with $0.1 \mathrm{mM}$ menadione for 3 hours. OGG1 level was found to be down-regulated due to NKX3.1 expression in the absence of menadione. However, OGG1 level was maintained upon menadione treatment as a cellular response to oxidative DNA damage regardless of NKX3.1 expression. Native expression of NKX3.1 in LNCaP cells was included to ensure the ectopic expression in PC-3 cells (Figure 7).

\subsection{OGG1-S326C polymorphic variant reduces OGG1-NKX3.1 co-localization}

LNCaP cells were transfected with pEGFP-OGG1-wt and pEGFP-OGG1-S326C in order to investigate if the cellular localization of the polymorphic variant as well as co-localization with NKX3.1 differs from the wild type. Cells were also treated with $10 \mathrm{nM}$ of synthetic androgen R1881 for 24 hours to enhance NKX3.1 expression and with $0.1 \mathrm{mM}$ menadione for 3 hours to induce oxidative DNA damage. It was determined that OGG1-S326C also localizes in the nucleus but a homogeneous expression pattern was observed instead of nuclear speckles possibly because of high level of ectopic expression. In addition, no co-localization with NKX3.1 was determined in control and menadione-treated cells. Upon enhanced NKX3.1 expression with 
R1881, S326C variant was observed not to co-localize with NKX3.1 although NKX3.1 expression can be seen in most of the OGG1-wt transfected cells in the absence and presence of menadione (Figure 8).

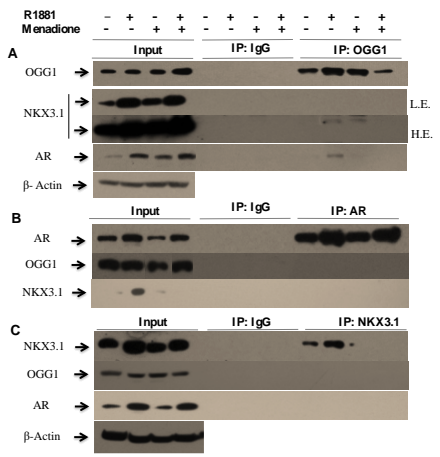

Figure 1. Physical protein-protein interaction analyses between OGG1, NKX3.1 and AR. LNCaP cells treated with R1881 $(10 \mathrm{nM}, 24 \mathrm{~h})$ and menadione $(0.1 \mathrm{mM}, 3 \mathrm{~h})$ and the protein extracts were subjected to immunoprecipitation by using antibodies specific to OGG1, AR, and NKX3.1. Extracts were immunoprecipitated with (A) non-spesific IgG or OGG1 antibody, (B) non-spesific IgG or AR antibody, (C) non-spesific IgG or NKX3.1 antibody. Protein extracts (input) and IP samples were immunoblotted with OGG1, NKX3.1, AR, and $\beta$-actin antibodies. L.E.: Low Exposure, H.E.: High Exposure. $\beta$-actin was used to ensure the equality of protein loading.

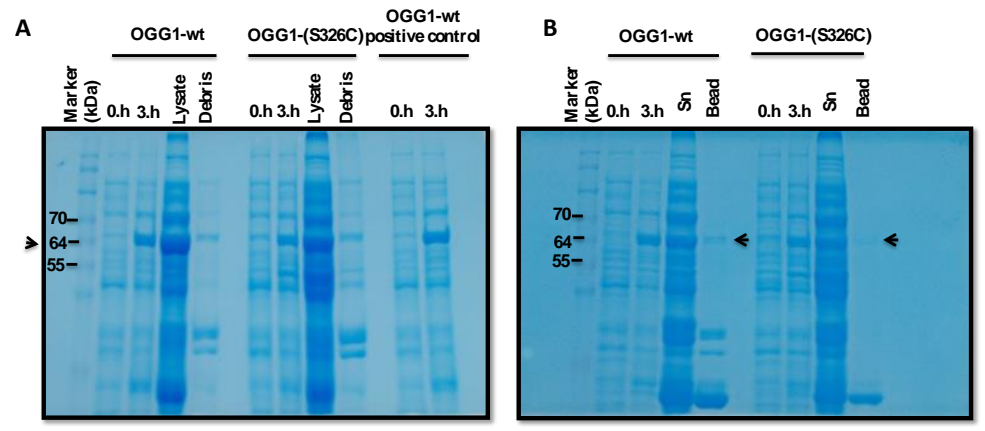

Figure 2. Coomassie blue staining to show induction of E. coli DH5 $\alpha$ transformants by $1 \mathrm{mM}$ IPTG for expressing recombinant GST-OGG1 (wt/S326C) proteins and control of purification by GST-agarose bead. (A) GST-OGG1(wt/S326C) protein isolation in the lysate was detected on $64 \mathrm{kDa}$. (B) GSTOGG1(wt/S326C) proteins captured by glutathione agarose beads (bead lanes) were detected on $64 \mathrm{kDa}$. Each lane shows the protein extracts as 0 h.: E. coli protein extract before IPTG induction, 3h.: E. coli protein extract at 3rd hour of IPTG induction, Lysate: Soluble protein fraction, Debris: Insoluble protein fraction, Sn: Supernatant obtained after bead purification, Bead: Glutathione agarose beads that capture recombinant proteins. Expected molecular weight of GST-tagged OGG1 fusion proteins is $64 \mathrm{kDa}$.

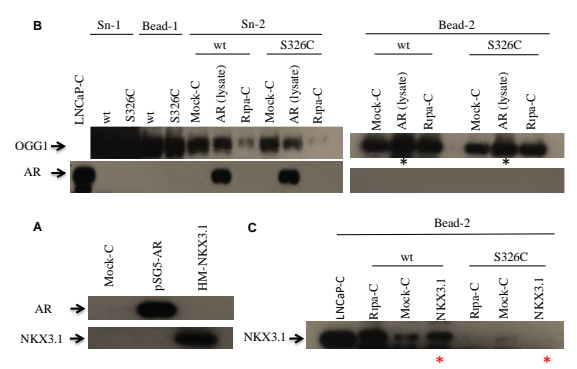

Figure 3. GST-pull down assay showing OGG1-NKX3.1 interaction. GST-OGG1(wt/S326C) proteins that precipitated by using glutathione agarose beads were incubated with PC-3 protein lysates that ectopically express AR or NKX3.1 proteins and the samples were then separated on polyacrylamide gel, electrotransferred to PVDF membrane and immunoblotted with the antibodies. (A) Ectopic expression of AR and NKX3.1 in PC-3 cells. Immunoblotting to examine the protein-protein interaction between (B) GSTOGG1(wt/S326C) proteins and AR protein with anti-OGG1 antibody and anti-AR antibody. The labeled lanes with black star implied that there is no interaction. (C) GST-OGG1(wt/S326C) proteins and NKX3.1 protein with NKX3.1 antibody. The labeled lanes with red star implied that there is interaction between 
OGG1 and NKX3.1 and S326C mutation alleviates the interaction. LNCaP sample was used to show the molecular weight of native AR and NKX3.1.

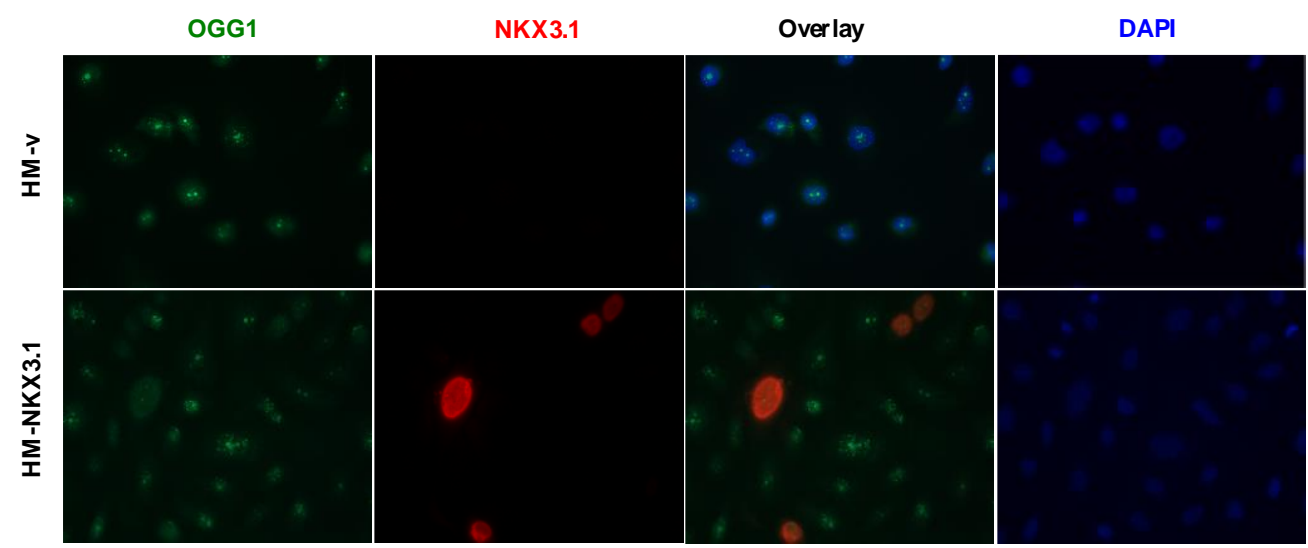

Figure 4. Immunofluorescence microscopy images showing cellular localization of OGG1 and NKX3.1 in PC-3 cells transfected with either HM-v or HM-NKX3.1. Alexa Fluor-488 (green) labeling shows OGG1, Alexa Fluor-594 (red) labeling shows NKX3.1 and DAPI (blue) staining shows nuclear DNA. Nuclear localization of OGG1 into nuclear speckles in untransfected PC-3 cells wasn't observed in ectopically NKX3.1-expressing cells.

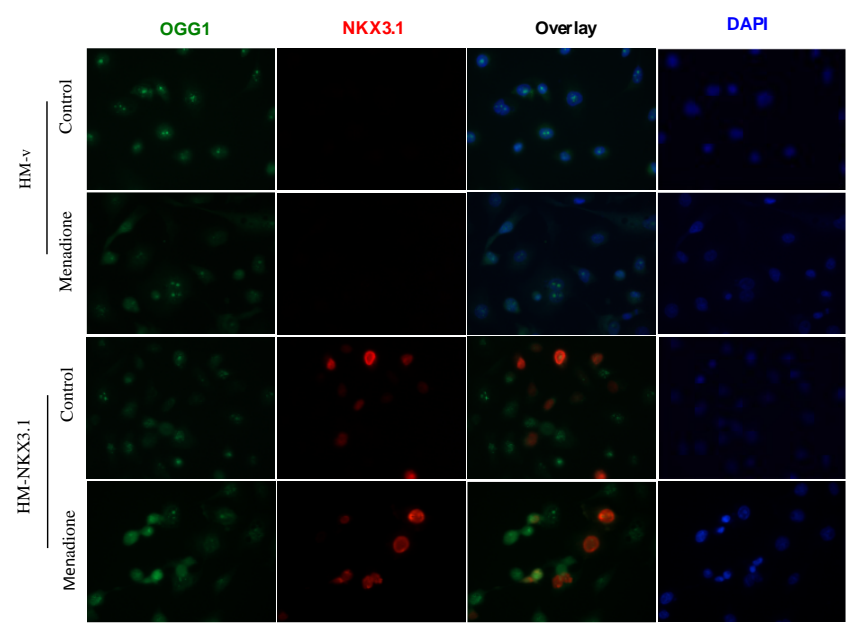

Figure 5. Immunofluorescence microscopy images showing OGG1 and NKX3.1expressions in PC-3 cells tranfected with either HM-v or HM-NKX3.1 and treated with menadione (0.1 mM, 3 hours). Alexa Fluor488 (green) labeling shows OGG1, Alexa Fluor-594 (red) labeling shows NKX3.1 and DAPI (blue) staining shows nuclear DNA.

\section{DISCUSSION}

As the regulatory roles of AR and NKX3.1 in recognition and repair of DNA damage in prostate cells were revealed, research of direct protein-protein interaction of them with OGG1 as well as OGG1-S326C variant in oxidative stress conditions became to be necessary to figure out the potential of OGG1 as a therapeutic target for prostate cancer cure. In this study, we firstly investigated the molecular factors that regulate the protein-protein interaction of OGG1 with AR and NKX3.1 in order to understand the link between OGG1 functionality and oxidative DNA damage regulation in prostate carcinogenesis. We showed that OGG1 is in physical interaction with AR and NKX3.1 in native conditions, which LNCaP prostate cancer cells do natively express OGG1, AR and NKX3.1 and this interaction is enhanced when the cells were treated with synthetic androgen R1881 or oxidative stress inducer menadione. In addition, the GST-pull-down results supported the interaction of OGG1 with only NKX3.1 but not AR in ectopically AR/NKX3.1expressing PC-3 cells. Our immunoprecipitation results also confirmed the study of Bowen et al. showing the interaction of OGG1 both with AR and NKX3.1 upon treatment by etoposide, DNA double strand break inducer, in LNCaP cells using the native IP method [22]. So, in the case of each cellular stress and damage 
conditions, OGG1 interacts with NKX3.1 and AR to contribute to the repair of DNA damage in prostate cells especially under oxidative damage conditions, which require BER activation.

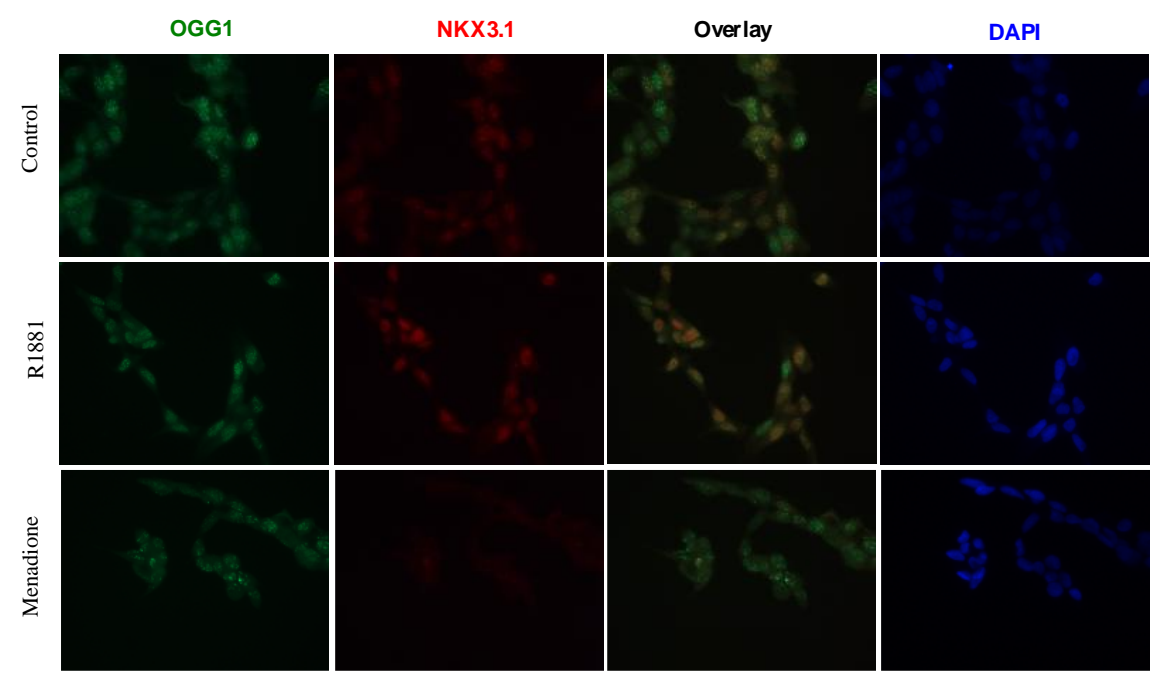

Figure 6. Immunofluorescence microscopy images showing cellular localization of NKX3.1 and OGG1 in LNCaP cells treated with R1881 (10 nM, 24 hours) and menadione ( $0.1 \mathrm{mM}, 3$ hours). Alexa Fluor-488 (green) and Alexa Fluor-594 (red) labelings show OGG1 and NKX3.1 respectively and DAPI (blue) staining shows nuclear DNA.

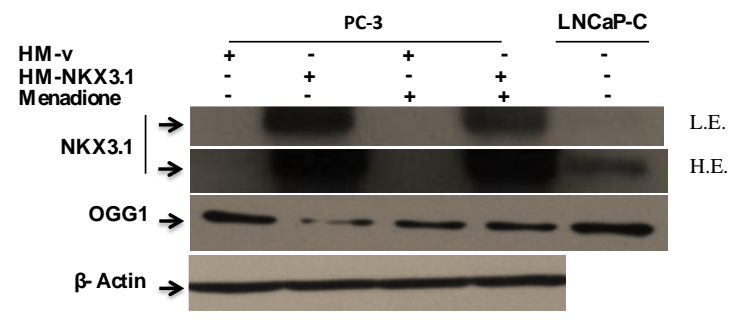

Figure 7. OGG1 expression in PC-3 cells after HM-v or HM-NKX3.1 transfection and menadione (0.1 mM, 3 hours) treatment was shown by western blotting. Native NKX3.1 expression in LNCaP cells was detected to ensure the ectopic expression in PC-3 cells.

Campalans et al. discovered that OGG1 enzyme accumulates more in nuclear spots in the presence of ROS but the accumulation in these sub-nucleus structures decreases when there is sufficient antioxidant response in the cell [27]. Consistent with this study, OGG1 expression was observed to exist as nuclear speckles most probably at the oxidative DNA damage sites in the nucleus. Further, regarding the expression pattern of OGG1, loss of speckle formation as well as reduced protein level also detected in ectopically NKX3.1 expressing PC-3 cells. Induction of oxidative DNA damage by menadione treatment was observed to enhance OGG1 protein level only in un-transfected cells that do not express NKX3.1. It has been known that NKX3.1 has a regulator role in oxidative stress and activates genes functioning in antioxidant response $[14,15]$ in prostate cells, which makes NKX3.1 an important tumor suppressor for prostate carcinogenesis. Since, menadione enhanced OGG1 expression only in un-transfected PC-3 cells, it is suggested that high level of NKX3.1 in transfected cells should be capable to regulate oxidative stress and consequently reduce oxidative DNA damage by triggering an adequate antioxidant response, resulting in less need to OGG1 repair function. In addition, OGG1 level was found to down-regulated due to NKX3.1 expression in the absence of menadione possibly due to reduced oxidative stress by NKX3.1. However, OGG1 level was maintained upon menadione treatment regardless of NKX3.1 expression as a cellular response to oxidative DNA damage. Therefore, it is suggested that OGG1 level is regulated depending on the efficiency of NKX3.1 function on regulating oxidative stress and consequently reducing DNA damage.

Interaction context of OGG1 with NKX3.1 is also related to cellular oxidative stress and subsequent damage formation induced by endogenous or exogenous factors. Since our results showed that NKX3.1 level decreased upon induction of oxidative damage by menadione treatment implying that DNA damage level higher than the repair capacity of the cell leads the cell to suppress survival factors such as NKX3.1, 
interaction of OGG1 and NKX3.1 is suggested to be necessary mostly in basal or tolerable level of oxidative DNA damage.

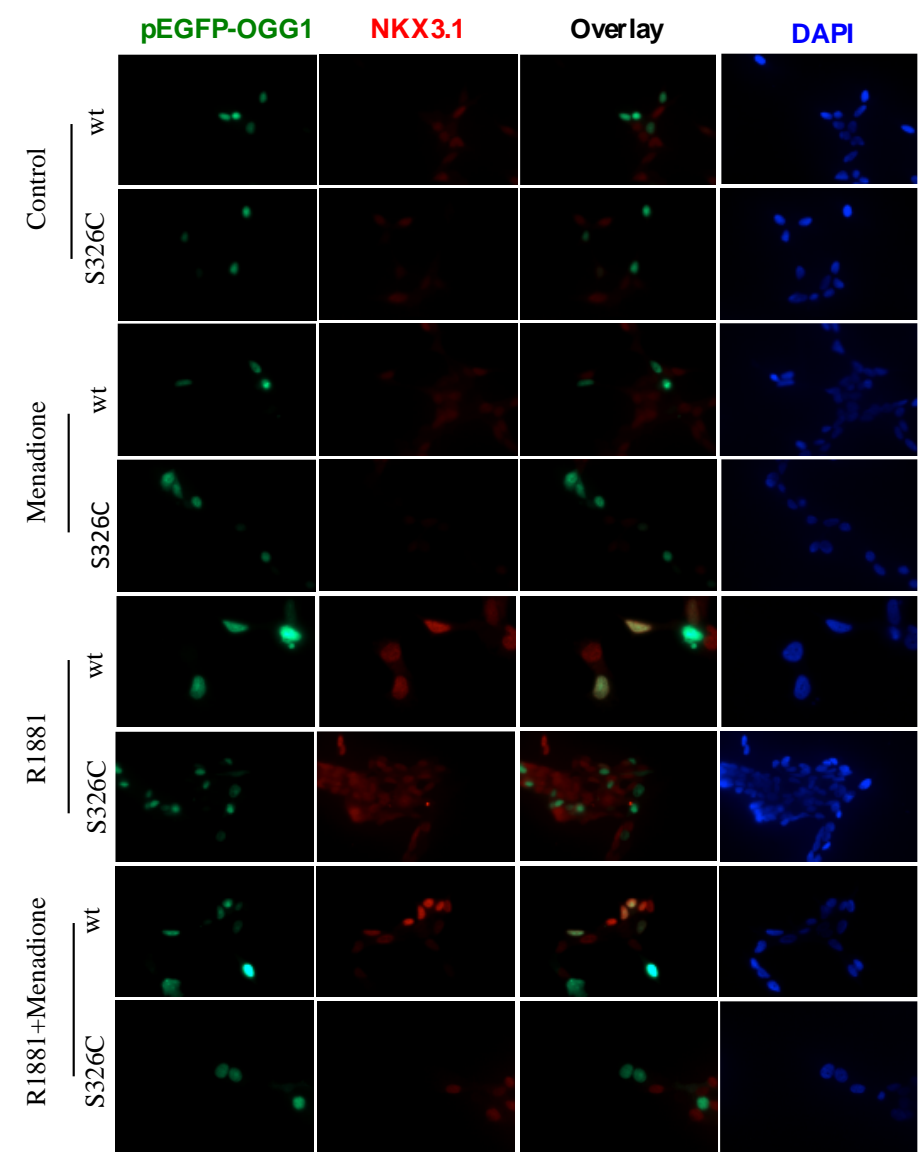

Figure 8. Immunofluorescence microscopy images showing expressions of NKX3.1 and OGG1. LNCaP cells transfected with either pEGFP-OGG1-wt or pEGFP-OGG1(S326C) and treated with R1881 (10 nM, 24 hours) and menadione (0.1 mM, 3 hours). Alexa Fluor-594 (red) labeling shows NKX3.1 and DAPI (blue) staining shows nuclear DNA.

There are many studies investigating the effect of S326C polymorphism on OGG1 function. In our study, we found that OGG1-S326C polymorphism results in decreased protein-protein interaction between OGG1 and NKX3.1. Further, confirming this result, no co-localization of OGG1-S326C with NKX3.1 was determined in control and menadione-treated LNCaP cells. Although NKX3.1 expression was observed in most of the OGG1-wt transfected cells, S326C variant was detected not to co-localize with NKX3.1 even though enhanced NKX3.1 expression with R1881, which might be result in reduced repair of oxidative DNA damage leading prostate carcinogenesis. In the literature, there are conflicting results regarding contribution of S326C polymorphism to cancer predisposition. Reduced activity of OGG1-S326C variant was confirmed by accumulation of mutations under conditions of oxidative stress [28]. In addition, Dantzer et al. showed that OGG1-S326C has decreased functionality compared to its natural form [29]. However, another study reported that the polymorphic variant does not lead to functional loss to make a significant difference in cancer cases [30]. When our results have been evaluated with the current literature, it is concluded that OGG1-S326C polymorphic variant might be less functional that the wild type, however, OGG1-S326C should co-exist with other oxidative DNA-damage/repair-related cellular factors in the cell in order to be related to cancer predisposition. Supporting this idea, nitric oxide was found to reduce the oxidative DNA damage repair in OGG1 variant cells leading to increased genetic instability and malignant transformation in carriers of this variant allele [31].

\section{CONCLUSION}

When all the results are evaluated, interaction of OGG1 with AR and NKX3.1 is necessary especially at tolerable levels of oxidative DNA damage and since the less physical interaction of OGG1-S326C with 
NKX3.1, this variant form might lead to insufficient repair of oxidative DNA damage leading prostate carcinogenesis.

\section{MATERIALS AND METHODS}

\subsection{Cell culture and treatments}

LNCaP and PC-3 cells were obtained from the American Type Culture Collection (ATCC, Manassas, VA, USA). LNCaP cells were propagated as recommended using RPMI 1640 medium supplemented with $10 \%$ FBS, PC-3 cells were propagated using DMEM-F12 with 5\% FBS, L-glutamine (2 mM), penicillin and streptomycin $(100 \mathrm{U} / \mathrm{mL})$ at $37^{\circ} \mathrm{C}$ in the presence of $5 \% \mathrm{CO}_{2}$. Menadione was purchased from Sigma-Aldrich and prepared freshly before each use. Androgen treatment was performed using R1881 (10 nM) for $24 \mathrm{~h} \mathrm{[32].}$

\subsection{Transfection}

The NKX3.1 open reading frame was amplified and cloned into the pcDNA4/HisMax-TOPO vector (Invitrogen, MA, USA) according to the manufacturer's instructions to obtain HM-NKX3.1 and HM-vector constructs. pEGFP-OGG1-wt and pEGFP-OGG1-S326C vectors are kindly gift from J. Pablo Radicella (François Jacop Institute of Biology, Paris). The AR open reading frame was amplified and cloned into the pSG5 vector according to the manufacturer's instructions to obtain pSG5-AR construct. The transfections were performed using the Dharmafect II transfection reagent (Dharmacon) for $24 \mathrm{~h}$. Briefly, $5 \times 10^{5}$ cells were seeded into $6 \mathrm{~cm}$ plates or $2.5 \times 10^{5}$ cells into 6-well plates. Next day, the medium was changed to antibiotic free medium, and the transfection mix was prepared by adding $1 \mu \mathrm{g}$ DNA (tube 1) and $6 \mu \mathrm{l}$ of Dharmafect II (tube 2) into $100 \mu \mathrm{l}$ of serum/antibiotic-free medium separately. Each mix was incubated for $5 \mathrm{~min}$ at RT. Tube 1 is transferred into tube 2 and mixed by pipetting gently. The mix was incubated for $15 \mathrm{~min}$ at RT and added to cells drop wise. The cells were incubated for an additional $24 \mathrm{~h} \mathrm{[15].}$

\subsection{Immunoprecipitation}

Protein lysates $(500 \mu \mathrm{g})$ were subjected to immunoprecipitation using $2 \mu \mathrm{g}$ OGG1 or NKX3.1 or AR antibody at $4^{\circ} \mathrm{C}$ overnight. The antigen-antibody complexes were collected after incubation with $40 \mu 1 \mathrm{IP}$ matrix (Santa Cruz, Inc.) that contains the beads at $4^{\circ} \mathrm{C}$ for $4 \mathrm{~h}$. After centrifugation at max speed for $1 \mathrm{~min}$ at $4^{\circ} \mathrm{C}$, the pellets were washed with $500 \mu \mathrm{PBS}$ twice and PBS discarded by centrifugation, the collected beads were resuspended in $30 \mu \mathrm{l}$ RIPA buffer with protease inhibitor solution, and one half of each sample was used for the SDS-PAGE run [32].

\subsection{Transformation and GST-pull-down}

GST-OGG1-wt and GST-OGG1-S326C vectors are kindly gift from J. Pablo Radicella (François Jacop Institute of Biology, Paris). This plasmid vectors allow the expression of a fusion protein, OGG1-wt and OGG1-S326C proteins fused to the C-terminus of GST protein. Escherichia coli DH5 $\alpha$ transformed with the plasmid GST-OGG1-wt or GST-OGG1-S326C was grown at $37^{\circ} \mathrm{C}$ in LB broth containing $100 \mu \mathrm{g} / \mathrm{ml}$ ampicillin until the absorbance at $600 \mathrm{~nm}$ reached to 0.6 and induced by $1 \mathrm{mM}$ IPTG for at $37^{\circ} \mathrm{C}$ for 3 hours. Cells were collected and stored at $-86^{\circ} \mathrm{C}$ [33].

Lysis was performed with the solution containing STE $(10 \mathrm{mM}$ Tris- $\mathrm{HCl}, \mathrm{pH} 8.0,1 \mathrm{mM}$ EDTA, 150 $\mathrm{mM} \mathrm{NaCl}$ ), $10 \mathrm{mg} / \mathrm{ml}$ Lysozyme in water, $1 \mathrm{mM} \mathrm{DTT}, 10 \%$ Sarkosyl solution and 10\% Triton-X-100 and mixed thoroughly by inversion and sonicated for a total time of $1 \mathrm{~min}$. After centrifugation at $16000 \mathrm{rpm}$ for $20 \mathrm{~min}$ at $4^{\circ} \mathrm{C}$, the pellet (debris) was resuspended with PBS and supernatant (lysate) was resuspended with STE and screened SDS-PAGE gel by coomassie blue staining [33].

After glutathione agarose beads (50\% slurry) washed with TEN100 buffer (20 mM Tris pH 7.4, $0.1 \mathrm{mM}$ EDTA, $100 \mathrm{mM} \mathrm{NaCl}$ ), $400 \mu \mathrm{l}$ supernatant (lysate) containing the GST-tagged OGG1 proteins were incubated with the beads at rotator for $1 \mathrm{~h}$ at $4^{\circ} \mathrm{C}$. Centrifugation at $2000 \mathrm{rpm}$ for $1 \mathrm{~min}$ at $4^{\circ} \mathrm{C}$ performed, supernatant (Sn-1) and beads (Bead-1) separated and collected in new tubes. Protein lysates (100 $\mu \mathrm{g})$ obtained from PC-3 cells that ectopically expressed AR or NKX3.1 incubated with the GST-tagged OGG1 proteins and glutathione agarose bead mixture at rotator for $24 \mathrm{~h}$ at $4^{\circ} \mathrm{C}$. After centrifugation at $2000 \mathrm{rpm}$ at $4^{\circ} \mathrm{C}$ for $30 \mathrm{sec}$, supernatant (Sn-2) and beads (Bead-2) were separated and collected in new tubes. The bound proteins precipitated with glutathione-agarose beads (Bead-2) and collected in a new tube were resuspended in $30 \mu 1$ RIPA buffer with protease inhibitor solution, and one half of each sample was used for the SDS-PAGE run and immunoblotting with OGG1, NKX3.1 and AR antibodies [33]. 


\subsection{Western blotting}

For protein extraction, $\mathrm{LNCaP}$ cells were lysed using a modified RIPA buffer $(10 \mathrm{mM}$ Tris-Cl (pH: 8.0), $1 \%$ Triton X-100, 0.1\% SDS, 0.1\% Na deoxycholate, $1 \mathrm{mM}$ EDTA, $1 \mathrm{mM}$ EGTA, $140 \mathrm{mM} \mathrm{NaCl}$ ) containing protease and phosphatase inhibitors. Then, the concentrations were determined using the BCA assay (Sigma, UK). SDS-PAGE and western blots were performed under standard conditions with $50 \mu \mathrm{g}$ of protein lysate per lane. The proteins were separated on 10-12\% gels and transferred to PVDF membranes (Amersham, UK) using a wet transfer blotter. The PVDF membrane was blocked with 5\% dry milk in TBS-T (Tris-BufferedSaline solution containing $0.1 \%$ Tween 20). The primary and secondary antibody incubations were performed in TBS-T containing $0.5 \%$ dry milk at RT for $1 \mathrm{~h}$ or at $4^{\circ} \mathrm{C}$ overnight. The membranes were developed using the ECL prime reagent (Amersham, UK) for $5 \mathrm{~min}$ and were photographed using Kodak XRay films in a dark room [15].

\subsection{Immunofluorescence}

Cells were grown on coverslips and at the time of analysis, cells on coverslips were rinsed with PBS, fixed with methanol at $-20^{\circ} \mathrm{C}$ for $30 \mathrm{~min}$, permeabilized with $0.2 \%$ triton X-100 in PBS for 5 min on a shaker and blocked for 5 min using 1\% BSA in PBS. Primary antibodies (in 1\% BSA/PBS) were added and incubated in a humidified chamber for $1 \mathrm{~h}$, and cells were washed four times with PBS. Secondary antibody incubations were performed at RT for 20 min using Alexa Fluor 488/594 antibody. Finally, cells were washed four times with PBS and mounted on coverslips with $30 \%$ glycerol in PBS including $0.5 \mathrm{mg} / \mathrm{ml}$ DAPI and analyzed immediately using Leica DM4000B LED fluorescent microscope (Leica, Wetszlar, Germany). Images were captured using Leica imaging software [34].

\subsection{Antibodies}

The following antibodies were purchased from manufacturers: AR (Millipore, MA, USA), OGG1 (Abcam, Cambridge, UK) and $\beta$-actin (Sigma-Aldrich, Darmstadt, Germany). The NKX3.1 custom antibody was a gift from Dr. F. Saatcioglu (University of Oslo). Anti-rabbit IgG were purchased from Santa Cruz Biotechnology Inc. (Bergheimer, Germany). The HRP-conjugated anti-mouse and anti-rabbit antibodies (Amersham, Buckinghamshire, UK), Alexa Fluor 488/594 conjugated anti-mouse and anti-rabbit antibodies (Invitrogen, Carlsbad, CA, USA) were purchased and used as recommended [35].

Acknowledgements: We thank to J. Pablo Radicella (François Jacop Institute of Biology, Paris) for kindly sharing the GST-OGG1-wt, GST-OGG1-S326C, pEGFP-OGG1-wt, and pEGFP-OGG1-S326C plasmid vectors.

Author contributions: Concept - E.I., B.D.B.; Design - E.I., B.D.B.; Supervision - B.D.B; Resources - B.D.B.; Materials B.D.B; Data Collection \&/or Processing - E.I.; Analysis \&/or Interpretation - E.I., B.D.B.; Literature Search - E.I., B.D.B; Writing - E.I., B.D.B.; Critical Reviews - E.I., B.D.B.

Conflict of interest statement: The authors declared no conflict of interest.

\section{REFERENCES}

[1] Acharya A, Das I, Chandhok D, Saha T. Redox regulation in cancer: a double-edged sword with therapeutic potential. Oxid Med Cell Longev. 2010; 3(1): 23-34. [CrossRef]

[2] Finkel T. Oxidant signals and oxidative stress. Curr Opin Cell Biol. 2003; 15(2): 247-254. [CrossRef]

[3] Klaunig JE, Kamendulis LM, and Hocevar BA. Oxidative stress and oxidative damage in carcinogenesis. Toxicol Pathol. 2010; 38(1): 96-109. [CrossRef]

[4] Reuter S, Gupta SC, Chaturvedi MM, Aggarwal BB. Oxidative stress, inflammation, and cancer: how are they linked? Free Radic Biol Med. 2010; 49(11): 1603-1616. [CrossRef]

[5] Boiteux S, Radicella JP. The human OGG1 gene: structure, functions, and its implication in the process of carcinogenesis. Arch Biochem Biophys. 2000; 377(1): 1-8. [CrossRef]

[6] Ba X, Boldogh I. 8-oxoguanine DNA glycosylase 1: beyond repair of the oxidatively modified base lesions. Redox Biol. 2018; 14: 669-678. [CrossRef]

[7] Luna L, Rolseth V, Hildrestrand GA, Otterlei M, Dantzer F, Bjoras M, Seeberg E. Dynamic relocalization of hOGG1 during the cell cycle is disrupted in cells harbouring the hOGG1-Cys326 polymorphic variant. Nucleic Acids Res. 2005; 33(6): 1813-1824. [CrossRef] 
[8] Klungland A, Bjelland S. Oxidative damage to purines in DNA: role of mammalian Ogg1. DNA Repair (Amst). 2007; 6(4): 481-488. [CrossRef]

[9] Ames BN, Shigenaga MK, Hagen TM. Oxidants, antioxidants, and the degenerative diseases of aging. Proc Natl Acad Sci U S A. 1993; 90(17): 7915-7922. [CrossRef]

[10] Malins DC, Johnson PM, Wheeler TM, Barker EA, Polissar NL, Vinson MA. Age-related radical-induced DNA damage is linked to prostate cancer. Cancer Res. 2001; 61(16): 6025-6028. PMID: 11507046.

[11] Malins DC, Johnson PM, Barker EA, Polissar NL, Wheeler TM, Anderson KM. Cancer-related changes in prostate DNA as men age and early identification of metastasis in primary prostate tumors. Proc Natl Acad Sci U S A. 2003; 100(9): 5401-5406. [CrossRef]

[12] Olinski R, Zastawny TH, Foksinski M, Barecki A, Dizdaroglu M. DNA base modifications and antioxidant enzyme activities in human benign prostatic hyperplasia. Free Radic Biol Med. 1995; 18(4): 807-813. [CrossRef]

[13] Tam NN, Ghatak S, Ho SM. Sex hormone-induced alterations in the activities of antioxidant enzymes and lipid peroxidation status in the prostate of noble rats. The Prostate. 2003; 55(1): 1-8. [CrossRef]

[14] Debeleç Bütüner B, Korkmaz KS. NKX3.1 binding to GPX2, QSCN6, SOD1, and SOD2 promoters contributes to antioxidant response regulation via transactivation. Turkish Journal of Biology. 2014; 38(5): 640-647. [CrossRef]

[15] Debeleç Bütüner B, Ertunç N, Korkmaz KS. Inflammation contributes to NKX3.1 loss and augments DNA damage but does not alter the DNA damage response via increased SIRT1 expression. J Inflamm (Lond). 2015; 12: 12. [CrossRef]

[16] Abate Shen C, Banach Petrosky WA, Sun X, Economides KD, Desai N, Gregg JP, Borowsky AD, Cardiff RD, Shen MM. Nkx3.1; Pten mutant mice develop invasive prostate adenocarcinoma and lymph node metastases. Cancer Res. 2003; 63(14): 3886-3890. PMID: 12873978.

[17] Bethel CR, Faith D, Li X, Guan B, Hicks JL, Lan F, Jenkins RB, Bieberich CJ, De Marzo AM. Decreased NKX3.1 protein expression in focal prostatic atrophy, prostatic intraepithelial neoplasia, and adenocarcinoma: association with gleason score and chromosome 8p deletion. Cancer Res. 2006; 66(22): 10683-10690. [CrossRef]

[18] Bowen C, Bubendorf L, Voeller HJ, Slack R, Willi N, Sauter G, Gasser TC, Koivisto P, Lack EE, Kononen J, Kallioniemi OP, Gelmann EP. Loss of NKX3.1 expression in human prostate cancers correlates with tumor progression. Cancer Res. 2000; 60(21): 6111-6115. PMID: 11085535.

[19] Yang CC, Chung A, Ku CY, Brill LM, Williams R, Wolf DA. Systems analysis of the prostate tumor suppressor NKX3.1 supports roles in DNA repair and luminal cell differentiation. F1000Res. 2014; 3: 115. [CrossRef]

[20] Bowen C, Gelmann EP. NKX3.1 activates cellular response to DNA damage. Cancer Res. 2010; 70(8): 3089-3097. [CrossRef]

[21] Bowen C, Ju JH, Lee JH, Paull TT, Gelmann EP. Functional activation of ATM by the prostate cancer suppressor NKX3.1. Cell Rep. 2013; 4(3): 516-529. [CrossRef]

[22] Bowen C, Zheng T, Gelmann EP. NKX3.1 suppresses TMPRSS2-ERG gene rearrangement and mediates repair of androgen receptor-induced DNA damage. Cancer Res. 2015; 75(13): 2686-2698. [CrossRef]

[23] Weiss JM, Goode EL, Ladiges WC, Ulrich CM. Polymorphic variation in hOGG1 and risk of cancer: a review of the functional and epidemiologic literature. Mol Carcinog. 2005; 42(3): 127-141. [CrossRef]

[24] Zhang H, Xu Y, Zhang Z, Li L. The hOGG1 Ser326Cys polymorphism and prostate cancer risk: a meta-analysis of 2584 cases and 3234 controls. BMC Cancer. 2011; 11: 391. [CrossRef]

[25] Zhang Y, Newcomb PA, Egan KM, Titus Ernstoff L, Chanock S, Welch R, Brinton LA, Lissowska J, BardinMikolajczak A, Peplonska B, Szeszenia-Dabrowska N, Zatonski W, Garcia Closas M. Genetic polymorphisms in base-excision repair pathway genes and risk of breast cancer. Cancer Epidemiol Biomarkers Prev. 2006; 15(2): 353358. [CrossRef]

[26] Xu JF, Zheng SL, Turner A, Isaacs SD, Wiley KE, Hawkins GA, Chang BL, Bleecker ER, Walsh PC, Meyers DA, Isaacs WB. Associations between hOGG1 sequence variants and prostate cancer susceptibility. Cancer research. 2002; 62(8): 2253-2257. PMID: 11956079.

[27] Campalans A, Amouroux R, Bravard A, Epe B, Radicella JP. UVA irradiation induces relocalisation of the DNA repair protein hOGG1 to nuclear speckles. J Cell Sci. 2007; 120(Pt 1): 23-32. [CrossRef]

[28] Bravard A, Vacher M, Moritz E, Vaslin L, Hall J, Epe B, Radicella JP. Oxidation status of human OGG1-S326C polymorphic variant determines cellular DNA repair capacity. Cancer Res. 2009; 69(8): 3642-3649. [CrossRef] 
[29] Dantzer F, Luna L, Bjoras M, Seeberg E. Human OGG1 undergoes serine phosphorylation and associates with the nuclear matrix and mitotic chromatin in vivo. Nucleic Acids Res. 2002; 30(11): 2349-2357. [CrossRef]

[30] Dherin C, Radicella JP, Dizdaroglu M, Boiteux S. Excision of oxidatively damaged DNA bases by the human alphahOgg1 protein and the polymorphic alpha-hOgg1(Ser326Cys) protein which is frequently found in human populations. Nucleic Acids Res. 1999; 27(20): 4001-4007. [CrossRef]

[31] Moritz E, Pauly K, Bravard A, Hall J, Radicella JP, Epe B. hOGG1-Cys326 variant cells are hypersensitive to DNA repair inhibition by nitric oxide. Carcinogenesis. 2014; 35(6): 1426-1433. [CrossRef]

[32] Debeleç Bütüner B, Alapınar C, Varışlı L, Erbaykent Tepedelen B, Hamid SM, Gönen Korkmaz C, Korkmaz KS. Inflammation-mediated abrogation of androgen signaling: an in vitro model of prostate cell inflammation. Mol Carcinog. 2012; 53(2): 85-97. [CrossRef]

[33] Park DW, Kim SS, Nam MK, Kim GY, Kim J, Rhim H. Improved recovery of active GST-fusion proteins from insoluble aggregates: solubilization and purification conditions using PKM2 and HtrA2 as model proteins. BMB Rep. 2011; 44(4): 279-84. [CrossRef]

[34] Debeleç Bütüner B, Alapınar C, Ertunç N, Gönen Korkmaz C, Yörükoğlu K, Korkmaz KS. TNF alpha-mediated loss of beta-catenin/E-cadherin association and subsequent increase in cell migration is partially restored by NKX3.1 expression in prostate cells. PLoS One. 2014; 9(10): e109868. [CrossRef]

[35] Debeleç Bütüner B, Bostancı A, Özcan F, Singin Ö, Karamil S, Aslan M, Roggenbuck D, Korkmaz KS. Oxidative DNA damage-mediated genomic heterogeneity is regulated by NKX3.1 in prostate cancer. Cancer Invest. 2019; 37(2): 113-126. [CrossRef]

This is an open access article which is publicly available on our journal's website under Institutional Repository at http://dspace.marmara.edu.tr. 